\title{
In memoriam, András Gács
}

\section{Simeon Ball • Jan De Beule • Leo Storme • \\ Peter Sziklai · Tamás Szónyi}

Published online: 26 May 2010

(C) Springer Science+Business Media, LLC 2010

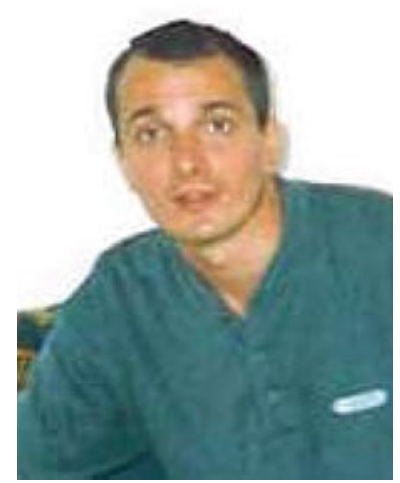

András Gács (1969-2009)

Communicated by D. Jungnickel.

S. Ball

Universitat Politècnica de Catalunya, Barcelona, Spain

e-mail: simeon@ma4.upc.edu

J. De Beule · L. Storme ( $\square)$

Ghent University, Ghent, Belgium

e-mail: 1s@cage.ugent.be

J. De Beule

e-mail: jdebeule@cage.ugent.be

P. Sziklai · T. Szőnyi

Eötvös Loránd University, Budapest, Hungary

P. Sziklai

e-mail: sziklai@cs.elte.hu

T. Szőnyi

e-mail: szonyi@cs.elte.hu 
On 28 October 2009, András Gács (Eötvös Loránd University, Budapest, Hungary) died suddenly at his home in Budapest. András was a regular visitor to Ghent, ever since he first visited the Department of Mathematics at Ghent University as one of the first TEMPUS students in 1994. András was one of the participants at the conference Galois Geometries and Applications 2009 (May 25-29, 2009, Ghent, Belgium) and we wish to dedicate the proceedings of this conference to his memory.

András is survived by his wife Zselyke Tófalvi and his daughter Bori.

He was a warm-hearted person with a special vein of humour (the jokes he made in secondary school 25 years ago are still cited by former classmates). He was always ready to help friends, colleagues and students in any way required. He enjoyed taking part in competitions, from students' math competitions to chess or bridge championships; moreover, he often invented funny or imaginary challenges to entertain himself and his friends. He wanted to be a top tennis player among mathematicians, a top mathematician among swimmers, a top swimmer among chess players and a top chess player among tennis players. He was fond of classical music with a notable collection of cd-s and he himself played the piano and the guitar at some basic level.

András was a talented young researcher whose work always received particular attention from the finite geometry community. His results led to invitations to give plenary talks at the Second Irsee Conference in 2006 and Combinatorics 2008.

András graduated from Eötvös Loránd University in 1993 and obtained his $\mathrm{PhD}$ degree in 1997. In his $\mathrm{PhD}$ thesis entitled The Rédei Method in Finite Geometry he started to work on blocking sets in Galois planes of prime order. The starting point was a Newton-WaringGirard type formula for the "mixed" power sums and symmetric polynomials of two subsets of $\operatorname{GF}(q)$. Later on he developed more polynomial techniques and applied them to blocking sets. One of the strongest techniques, called the Gács method in a recent survey paper by Simeon Ball, is based on counting the dimension of certain polynomial spaces.

András liked problems that are easy to state and difficult to prove. Most of his research was about substructures of finite affine and projective spaces, such as blocking sets, arcs, $(q+t, t)$ arcs of type $(0,2, t)$, semiovals, maximal partial spreads. Even though he employed a wide range of methods from combinatorics, through geometry to the probabilistic method, his main skill was the ingenious use of the polynomial method.

András was not only a strong researcher but also an enthusiastic lecturer. He always wanted to entertain his audience and put a lot of effort in preparing the jokes of his talks. He attracted gifted PhD students (Péter Csikvári, Tamás Héger, Zoltán Lóránt Nagy) and, together with them, worked on combinatorial problems from algebraic combinatorics to extremal graphs.

In total he is (co)-author of more than 20 publications. His coauthors are Alderson, Ball(3), Blokhuis, Cossidente, De Beule, Héger(3), Lovász, Mengyán, Nagy, Pálvölgyi, Siciliano, Sziklai(4), Szőnyi(6) and Weiner(5). His results will continue to inspire many researchers in Galois geometries. The articles in the proceedings of Galois Geometries and Applications 2009 are a tribute to his work. 